Document downloaded from:

http://hdl.handle.net/10251/49920

This paper must be cited as:

Crespo Amorós, JE.; Parres, F.; Nadal Gisbert, AV. (2012). Comparative study of the presence of latex and polychloroprene in the behavior of sintered powder EPDMCR, ethylene-propylenediene-monomer crumb rubber. Journal of Elastomers and Plastics. 44(2):127-144. doi:10.1177/0095244311418318.

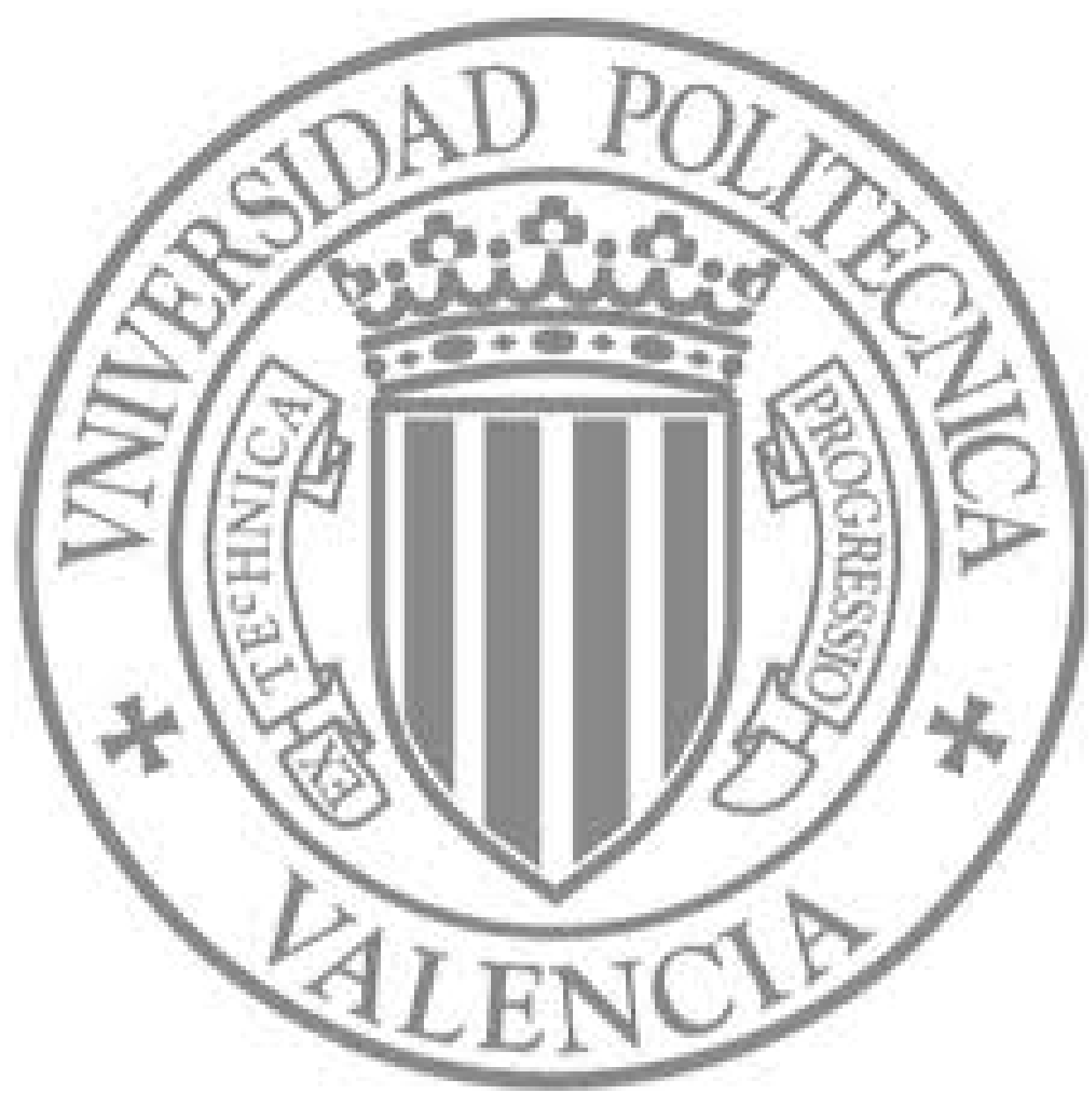

The final publication is available at

http://dx.doi.org/10.1177/0095244311418318

Copyright SAGE Publications (UK and US) 


\title{
COMPARATIVE STUDY OF THE PRESENCE OF LATEX AND \\ POLYCHLOROPRENE IN THE BEHAVIOR OF SINTERED POWDER EPDMCR, ETHYLENE-PROPYLENE-DIENE-MONOMER CRUMB RUBBER
}

\author{
J. E. Crespo ${ }^{\mathrm{a}}$, F. Parres $^{\mathrm{b}}$, A. Nadal ${ }^{\mathrm{c}}$ \\ Polytechnic University of Valencia \\ Mechanical and Materials Engineering Department \\ Plaza Ferrandiz y Carbonell 1, P.O Box 03801 Alcoy, (Alicante) Spain. \\ a) jocream@dimm.upv.es; ${ }^{b)}$ fraparga@dimm.upv.es; ${ }^{c)}$ anadal@mcm.upv.es
}

\begin{abstract}
In this work, the mechanical behavior of sintered waste material of Ethylene-PropyleneDiene-Monomer Crumb Rubber (EPDMCR) is analyzed, optimizing the temperature and compression pressure. The results obtained showed that an increase in temperature and compression pressure gives a significant improvement in the mechanical properties of the material. We later mixed the EPDMCR particles with different percentages of adhesives with the aim of further improving the mechanical performance obtained from the sintered particles. The adhesives used in this study were latex and polychloroprene, and the optimum mechanical performance obtained came from mixes with polychloroprene, using a mix with $50 \%$ adhesive. The study was concluded with an analysis of images of the material using a scanning electron microscope (SEM), in order to observe the EPDMCR-Adhesive interaction.
\end{abstract}

Keywords: adhesion, mechanical properties, EPDMCR, polychloroprene, latex, sintering 


\section{Introduction}

Natural rubber and synthetic rubber are materials that have been widely studied, both as individual materials as well as mixed with different plastics [1-5].

The ethylene-propylene-diene-monomer (EPDM) are the elastomers that have seen the greatest growth in use since their appearance in 1963. They represent $7 \%$ of the world's rubber consumption, and their various applications represent the second most used rubber product, coming second only to natural rubber for pneumatic tyres [6].

The characteristic of this material that make it useful for the industry is its resistance to oxidation. Diene is incorporated into the material in the final polymerization process, and helps create an elastomer which is resistant to oxidation as well as giving a microcrystalline structure which is not destroyed in any of the processing operations (it doesn't need waxes or antioxidants). Other properties worth highlighting are its resistance to exposure to weather and atmospheric agents; it is extremely resistant to heat, withstanding temperatures between $-15^{\circ} \mathrm{C}$ and $+130^{\circ} \mathrm{C}$; it is resistant to rainwater and waste water; it has good electrical resistance properties; it is easy to process, both in extrusion and moulding manufacturing processes and has the advantage over the other elastomers of being resistant to ozone $\left(\mathrm{O}_{3}\right)$.

The principal use of EPDM (more than a third of total world production) is in car industry applications such as hoses, joints and seals, and in building and construction applications such as seals, laminated floors, joints and cable coverings.

Contrary to the other rubber parts in cars, for example: tyres, EPDM rubber has received much less attention in relation to the question of recycling and the search for alternative uses for the material once its life cycle is concluded [7-11]. Respect to the research concerning the recycling of EPDM would include the following references $[6,8,10-16]$. 
Once EPDM has finished its useful life in the application for which it was originally designed, the material is available as a waste product. One of society's problems is how to give to the residue a added value, so that it may be used in other applications, given that normally it is not reincorporated in the same applications that it was made for, or if it is reincorporated, only in small quantities, insufficient to take real advantage of the great quantities of waste generated with this material [17].

The application of compatible adhesives and treatments to recycled elastomeric rubber particles improves the interaction between the waste particles with the aim of improving the properties of the material obtained [2, 18-30].

Another possibility to recover and obtain added value of EPDMCR is high temperature devulcanization $[31,32]$. There is also a variant on this technique, recycling EPDM using ultrasound $[33,34]$ along with a devulacanizing agent such as amines $[32,35]$ or diphenyl disulphide, which along with high temperature processing facilitates the devulcanization reaction.

These changes produced in the internal morphology of the material, aimed at improving the properties of the material, were observed using a scanning electron microscope (SEM) by [32, 35-38], carrying out a study of the fractures, in which they analyzed the fracture areas and the interaction produced by the different phases present in the material, with the objective of understanding the behavior of the material obtained [3, 39].

The present work consists of carrying out a study on the influence that the use of adhesives exerts on the mechanical behaviour of recycled material. The use of different adhesives; latex and polychloroprene has been analyzed, in order to understand their influence on the mechanical properties of the products obtained. The sample of 
composite material using EPDMCR residues and adhesives has been obtained by means of sintering. The interaction produced between particles and the adhesive is what produces the final characteristics of the material obtained.

\section{Methods}

\subsection{Materials}

In this research, we used ethylene-propylene-diene-monomer crumb rubber (EPDMCR) elastomeric waste from shredded defective watertight joints, provided by the company Caucho Industrial Verdu S.L. (Alcoy, Spain) with an bulk density 0,46 gr/ $\mathrm{cm}^{3}$, and with a compression factor of 1,54 of EPDMCR shredded particles at $25 \mathrm{Mpa}$, considering the compression factor as relationship between the initial volume of powder and the final volume obtained at this pressure. The residue of EPDMCR was obtained by means of a non cryogenic grinder. The adhesives used in this study were latex L-18 (Natural rubber adhesive dispersed in water, preserved with low ammonia content $(<0.29 \%)$. CAS No: 9006/04/6. Containing less than $0.1 \%$ zinc oxide and tetra methyl thiuram disulfide (TMTD)) and a polychloroprene 575 (Synthetic rubber adhesive in water dispersion. Components: 2-chlorine-1,3-butadiene homopolymer, CAS No. 9010-98-4). They have a maximum working temperature of up to $180^{\circ} \mathrm{C}$. These adhesives were provided by the company Adhesivos Kefren S.A. (Alicante, Spain).

\subsection{Sample preparation}

We first carried out a granulometric study of EPDMCR particle waste using a CISA SIEVE SHAKER sieve, model RP09 (Barcelona, Spain) with a waste sample of 300 grams. The series of sieves used were 63, 125, 250, 500, 1000 and $2000 \mu \mathrm{m}$. Later, the elastomeric waste was mixed with different adhesives. The proportions studied in this 
research were obtained using a K.A.P.L. orbital mixer, model 5KPMS (St Joseph, Michigan, USA) with the aim of homogenizing the mix.

\subsection{The sintering process}

The sintering process was carried out using a Robima S.A. (Valencia, Spain) press with a Dupra S.L. (Castalla, Spain) hot plate, with a maximum temperature of $240^{\circ} \mathrm{C}$, where we obtained, by means of an aluminium mould, Laminates of $180 \times 175 \mathrm{~mm}$ with a thickness of $4 \mathrm{~mm}$. The pressure applied on the mould varied between 1.4-3.0 MPa, and the temperature between $180-240^{\circ} \mathrm{C}$. We later used the results obtained on the optimum temperature and pressure in the sintering process for the consequent mix with the adhesives used in this study. Once the setting process was completed, the samples were cut according to ISO 527 using a MEGA KCK-15-A hydraulic press (Melchor Gabilondo S.A., Vizcaya, Spain).

\subsection{Mechanical testing}

The tensile properties of the samples were obtained using the universal testing machine ELIB 30 (S.A.E. Iberstest, Madrid, Spain) according to regulation ISO 527. The load cell employed had a capacity of $5 \mathrm{kN}$ and the displacement velocity of the applied clamp was $50 \mathrm{~mm} / \mathrm{min}$. The average numbers of test samples tested were seven, at room temperature for each formulation in this study and the results obtained give the mean values. Shore D hardness was measured using a Baxlo durometer (Baxlo, Barcelona, Spain) according to ISO 868.

\subsection{Morphological study}

The study of the failure mechanisms was conducted by directly observing the morphology of the fracture surface of the tensile test specimens. Scanning electron microscopy was applied in order to analyse the polymer fractures, using a FEI 
QUANTA 200 (FEI COMPANY, Hillsboro, USA). The micrographs were obtained in the microscope in ambiental mode (ESEM), which does not require the coating of gold or any other material for a correct visualisation.

\section{Results and discussion}

Firstly, we carried out a granulometric study of the waste used, which was composed of shredded particles of EPDMCR. This study showed the distribution of the different sized particles, and their proportions within the EPDMCR material used in this research. Fig. 1 shows the distribution obtained, and here we can see that in this shredded material is predominantly made up of particles with sizes of $500 \mu \mathrm{m}$ and $250 \mu \mathrm{m}$, representing $50 \%$ and $45 \%$ respectively of the total weight.

Figure 1.

Having carried out a granulometric analysis of residue, we then studied the sintering of the EPDMCR materials. The conditions of the sintering process applied to the material are between 1.4-3.0 MPa of compression pressure and a temperature between 160$220^{\circ} \mathrm{C}$.

In Figure 2 we can see how the tensile strength of the material increases as the applied pressure and temperature are increased. This trend is valid until up to the sintering pressure of $2.3 \mathrm{MPa}$, after which, the tensile strength begins to decrease. The results indicate also that the optimum temperature to gain maximum tensile strength in the material is $240^{\circ} \mathrm{C}$. The increase of tensile strength with pressure and temperature is justified for the sintering processed itself, pressure promotes and elastic deformation that increases the contact point between particles, and temperatures promotes the crosslinking in these points, due that for the vulcanization of EPDM, sulfur is used [40]. 


\section{Figure 2.}

Concerning the elastic modulus, as seen in Figure 3, there is a decreasing linear trend coinciding with an increase in compression pressure and temperature. To better understand the mechanical properties of the sintered product, it is important to take into account: first; that the EPDMCR was obtained from shredded elastomeric EPDM whose vulcanization was carried out using sulphur; and second: That in the process joining, the particles of EPDM is based on the presence of $-\mathrm{Sx}$ - links; which through a process of thermal activation $[14,41,42]$ generate free sulphur, which moves by diffusion toward the points of contact between the particles. We have to consider that the shredding process, through thermal and mechanical effects, can generate dienes, such as saturated non-functional groups which are the potential points of union on the surface of the material, that effect has been reported in the references [14, 40, 42]. Greater pressure generates greater contact between the material particles, as does the temperature which softens the EPDMCR. The best properties are obtained with the maximum temperature, as was to be expected, and when combined with the previously mentioned effects produce a more elastomeric natural material.

Figure 3.

The elongation at break obtained, Figure 4, follows the same pattern as tensile strength, where there is a steady increase up to a maximum, which occurs once again at $240^{\circ} \mathrm{C}$ and 2.3 MPa sintering pressure. This result confirms the achievement through sintering of a product that is elastomeric in nature, and that maintains the properties of the residue material, as explained earlier.

\section{Figure 4.}


When we analyzed hardness, Figure 5, we observed that this decreased when the sintering temperature was increased. This behavior was as we expected, as the material becomes less rigid as the sintering temperature and pressure are increased.

In this first part of the work, we can conclude that the optimum sintering conditions are $240^{\circ} \mathrm{C}$ and $2.3 \mathrm{MPa}$ of compression pressure as this gives the sintered material its best mechanical characteristics.

Figure 5.

Having concluded the study of the sintering process and identified the optimum sintering conditions, we now move on to the study of rubber adhesives, with the objective of improving the adhesion and interaction between the EPDMCR particles. One of the parameters that must be considered with the use of adhesives is their recommended temperature for use, provided by the manufacturer, as this may influence the sintering temperature in this part of the research. The maximum temperature at which these adhesives can be used is usually around $180^{\circ} \mathrm{C}$, and is therefore lower than the optimum sintering temperature of $240^{\circ} \mathrm{C}$, obtained in the first part of the paper. We must consider that the sintering process involves different binding mechanisms that those developed through the use of adhesives, and these mechanisms are activated in the sintering process at higher temperatures as has been justified above. This means we had to reconsider the maximum temperature for use with adhesives in this part of the study. Therefore, the sintering conditions applied were between $180-200^{\circ} \mathrm{C}$ and $2.3 \mathrm{MPa}$ of pressure.

Firstly, we analyzed the behavior of the EPDMCR with the latex adhesive (L-18). In Figure 6 we can see the evolution of tensile strength in function of the percentage of adhesive, reducing this for all percentages of adhesive used in comparison with 
EPDMCR sintered without adhesive. In percentage values, the addition of 5\% adhesive, leads to a reduction in mechanical resistance of about $50 \%$ at whichever temperature was used.

\section{Figure 6.}

The stiffness of the material increases with temperature, Figure 7, although in the samples submitted to $180^{\circ} \mathrm{C}$ the increase in values is much more defined, due to the temperature being greater than that recommended for the adhesives. This result seems to indicate a low adhesion of latex on the EPDMCR residue material. The effect of sintering is greater at $200^{\circ} \mathrm{C}$ and thus it was predictable that we would obtain a more elastomeric material.

\section{Figure 7.}

The elongation at break confirms the low adhesion of the latex (L-18) on the EPDMCR particles, and it is evident that weak unions cause the presence of cracks which in turn cause slight deformation. Once again, the best results were obtained with EPDMCR sintered without adhesives. In this case, the addition of only 5\% latex (L-18) leads to an elongation at break decrease of $50 \%$ at both temperatures, Figure 8.

\section{Figure 8.}

In Figure 9, we can see the hardness values for the various mixtures in function of percentage of adhesive. Hardness in this case is conditioned by the stiffness of the material, where with 5\% latex (L-18) the highest values were obtained, once again at $180^{\circ} \mathrm{C}$

\section{Figure 9.}

The possible justification for the behavior of EPDMCR with latex (L-18) added corresponds to the hypothesis that a relationship between the sintering process and the phenomenon of adhesion caused by adhesive does not exist. In this case only one type 
of union between the particles exists, caused only by the sintering process and not caused by the adhesive. These unions can be seen in Figure 10 (a, b), which shows the adhesive to be localized, and not very dispersed, leading to the previously shown results and confirming the hypothesis proposed for the adhesion of the residue material with latex (L-18). The union achieved through adhesion is weaker than that achieved through sintering, and it is evident that the union points generated by adhesion weaken the material rather than strengthen it. The lower mechanical resistance produced with an increase in the percentage of adhesive confirms this fact. As shown in Figure $10(a, b)$ the points of union are of different magnitude. This implies the presence of unions more or less extensive. On the other hand, Figure $10 \mathrm{~b}$ shows that the union is of a filamentous and therefore weak.

Figure 10 (a, b).

Having studied the behaviour of EPDMCR residue with the adhesive L-18, we now proceed to the study with the adhesive polychloroprene (575).

In this case, when using polychloroprene 575, we observed that mechanical properties increase with an increase in the percentage of adhesive used independently of the temperature employed, obtaining very similar values. In Figure 11 we can see the evolution of tensile strength in function of the percentage of adhesive used. In this case we saw a linear increase alongside the increase in percentage of adhesive for both temperatures, obtaining an increase of $50 \%$ in tensile strength with an adhesive content of $50 \%$ with respect to the material sintered without adhesives.

\section{Figure 11.}

Concerning elastic modulus, as can be seen in Figure 12, the greatest stiffness of material is found at a temperature of $180^{\circ} \mathrm{C}$ and with an adhesive percentage of $25 \%$, showing an increase of $15 \%$ over the material sintered without adhesive. In this case, 
the increase in percentage of adhesive used causes a reduction in the stiffness of the material after $25 \%$, independently of the sintering temperature employed.

\section{Figure 12.}

The elongation at break of the material sintered with 575, Figure 13, shows a similar behavior to that produced in the tensile strength tests, in which a linear increase in elongation for all percentages of adhesive used, reaching a maximum at $50 \%$ of adhesive and a temperature of $200^{\circ} \mathrm{C}$. At these optimum conditions, the improvement obtained over the material sintered without adhesive is $78 \%$.

\section{Figure 13.}

Shore A hardness, Figure 14, shows values that increase in function of the percentage of adhesive added up to $25 \%$, sintered at $180^{\circ} \mathrm{C}$ produces the maximum values for shore $\mathrm{A}$ hardness. The increase produced in hardness with respect to the material sintered without adhesive is $31 \%$.

\section{Figure 14.}

These maximum values in the behavior of EPDMCR mixed with adhesive 575 corresponds to the hypothesis on the results of the sintering process and the phenomenon of adhesion caused by the adhesive, that is to say that in this case there are two types of union: between particle and particle in (due to sintering process) and between particle and particle due to adhesive. These unions between the residue material and the adhesive can be seen in Figure 15 (a, b), where we can see a good interaction between the adhesive and the matrix as the adhesive is well dispersed throughout the particles of the material. When we use the polychloroprene adhesive, the bonded joints, unlike those observed in the latex, have good adhesion on the particle surface, causing a major adhesive union by the adhesive coating on the particle, as we can see in the Figure 15b. This concurs with the hypothesis stated earlier in the paper on 
the results of the residue material mixed with adhesive 575. Contrary to what occurred with the addition of latex (L-18), we saw an increase in the resistance of the elongations, a fact which means we can conclude that the particle - particle union using polychloroprene adhesive is more resistant than that produced by sintering only. In fact, we saw an initial reduction in these properties with the first additions of adhesive as the low percentage of adhesive unions does not compensate for the number of unions lost through sintering. However, for percentages over $25 \%$ of adhesive, mechanical resistance and elongation increase, a fact which can be interpreted as the achievement of a sufficient number of unions to compensate for those lost in the sintering process. In Figure 12, the elastic modulus graph, the stiffness of the product increases up to a content of $25 \%$ of adhesive, after which the elasticity diminishes with the addition of more adhesive, a fact which indicates that the adhesive begins to form the matrix phase, almost completely covering the EPDMCR particle.

\section{Figure $15(a, b)$.}

To justify the behaviour of the sintered product, if we take into account equation (1) of Griffith [43] here $\mathrm{Gc}=$ toughness of the material, $\mathrm{E}=$ elasticity modulus and $\sigma^{2}=$ the tension that produces a crack sized $\mathrm{a}_{\mathrm{c}}$, then:

$$
\mathrm{a}_{\mathrm{C}}=\frac{\mathrm{G}_{\mathrm{c}} * \mathrm{E}}{\pi * \sigma^{2}}
$$

In the cases where adhesives were used, we are going to separate them into mixtures using latex (L-18) and mixtures in which polychloroprene was used. In the case of latex (L-18) we saw a constant decrease in elongation at break as well as mechanical resistance with an increasing percentage of adhesive, which caused a decrease in toughness $(\mathrm{Gc})$ much greater than the increases in elasticity modulus, due to the fact that the unions by adhesion are weak or scarce and always inferior in terms of resistance 
to the unions achieved by sintering, which supposes that if we compare the sintered product with the material in which latex adhesive was used, same size defects need a less mechanical tension to grow.

In the case of polychloroprene 575, we saw a process of inflection in resistance and elongation. Mechanical resistance and elongation at break decrease with the addition of adhesive up to a percentage of $25 \%$ at which point it shares more or less the same characteristics as the sintered material, depending on the sintering conditions. Above $25 \%$, the mechanical properties of the product increased and surpassed those of sintered material. We saw that after this percentage, the material becomes more elastic, (reduction in elasticity modulus). In effect, a compensation effect was produced between the loss of unions by sintering and appearance of unions by adhesive. This demonstrates the effectiveness of using adhesive in the case of polychloroprene 575 . $25 \%$ is the percentage of adhesive after which the mechanical resistance of the material increases along with elongation at break, and the elasticity modulus decreases, possibly due to two factors. The first factor is associated with the fact that the adhesive begins to form a matrix phase, and begins to impose its properties on the material, and secondly, the particle to particle adhesion is efficient and the size of possible defects decreases due to good coverage of adhesive of the particle and therefore good adhesion. If we look at equation (1) by Griffith, we can understand the reductions in value $\mathrm{a}_{\mathrm{c}}$ will cause, in an elastomeric product, an increase in tensile strength $(\sigma)$, a fact which does not occur with the use of latex (L-18). Given that both elastomers are in a water solution and have a similar density, the particle union by latex (L-18) is weak and the presence of defects (fissures and cracks) or their formation under low tension causes a loss in the mechanical properties of the product. 


\section{Conclusions}

From shredded particles of Ethylene-Propylene-Diene-Monomer Crumb Rubber (EPDMCR) processed using sintering and under optimum conditions of $240^{\circ} \mathrm{C}$ and pressure of $2.3 \mathrm{MPa}$, we can obtain a material with acceptable mechanical performance, due to good cohesion and interaction between the particles of the residue material. The incorporation of adhesives in the initial sintering process, in the case of polychloroprene 575 improves the mechanical performance of the material when sintered at a temperature of $180^{\circ} \mathrm{C}$ with $2.3 \mathrm{MPa}$ of pressure and with an adhesive content of $40 \%$ or more. This improvement was not produced when latex (L-18) was used, in whichever proportion, due to low dispersion and interaction of the adhesive in the EPDMCR matrix.

\section{References}

1. Osman, H, Ismail, $\mathrm{H}$ and Mariatti, M. The Effect of Recycled Newspaper Content and Size on the Properties of Polypropylene (PP)/Natural Rubber (NR) Composites. Polym.-Plast. Technol. Eng. 2008;47(1):23 - 29.

2. Crespo, J E, Parres, F and Nadal, A. Mechanical behavior analysis of sintered products of natural rubber crumb rubber (NRCR) using adhesives. Mat.-wiss. u. Werkstofftech. 2008;40(3):211-217.

3. Setua, D K and Gupta, Y N. On the use of micro thermal analysis to characterize compatibility of nitrile rubber blends. Thermochim. Acta. 2007;462(1-2):32-37.

4. Nakason, C, Kaesaman, A, Samoh, Z, Homsin, S and Kiatkamjornwong, S. Rheological properties of maleated natural rubber and natural rubber blends. Polym. Test. 2002;21(4):449-455.

5. Jincheng, W, Yuehui, C and Jihu, W. Novel Reinforcing Filler: Application to Natural Rubber (NR) System. J. Elastomer. Plast. 2005;37(2):169-180. 
6. Sutanto, P, Picchioni, E, Janssen, L, Dijkhuis, K A J, Dierkes, W K and Noordermeer, J W M. State of the art: Recycling of EPDM rubber vulcanizates. Int. Polym. Process. 2006;21(2):211-217.

7. Jacob, C, Bhowmick, A K, De, P P and De, S K. Utilization of powdered EPDM scrap in EPDM compound. Rubber Chem. Technol. 2003;76(1):36-59.

8. Jacob, C, Bhattacharya, A K, Bhowmick, A K, De, P P and De, S K. Recycling of ethylene propylene diene monomer (EPDM) waste. III. Processability of EPDM rubber compound containing ground EPDM vulcanizates. J. Appl. Polym. Sci. 2003;87(14):2204-2215.

9. Jacob, C, Bhowmick, A K, De, P P and De, S K. Studies on ground EPDM vulcanisate as filler in window seal formulation. Plast. Rubber Compos. 2002;31(5):212-219.

10. Jacob, C, De, P P, Bhowmick, A K and De, S K. Recycling of EPDM waste. II. Replacement of virgin rubber by ground EPDM vulcanizate in EPDM/PP thermoplastic elastomeric composition. J. Appl. Polym. Sci. 2001;82(13):3304-3312.

11. Jacob, C, De, P P, Bhowmick, A K and De, S K. Recycling of EPDM waste. I. Effect of ground EPDM vulcanizate on properties of EPDM rubber. J. Appl. Polym. Sci. 2001;82(13):3293-3303.

12. Grigoryeva, O P, Fainleib, A M, Tolstov, A L, Starostenko, O M, Lievana, E and Karger-Kocsis, J. Thermoplastic Elastomers based on recycled high-density polyethylene, ethylene-propylene-diene monomer rubber, and ground tire rubber. J. Appl. Polym. Sci. 2005;95(3):659-671.

13. Mathew, G, Singh, R P, Nair, N R and Thomas, S. Development and characterization of novel EPDM/NR prophylactic waste composites. J. Mater. Sci. 2003;38(11):2469-2481.

14. Morin, J E, Williams, D E and Farris, R J. A novel method to recycle scrap tires: High-pressure high-temperature sintering. Rubber Chem. Technol. 2002;75(5):955-968. 15. Rajeev, R S and De, S K. Thermoplastic elastomers based on waste rubber and plastics. Rubber Chem. Technol. 2004;77(3):569-578.

16. Stark, F J. A New Method for Using Recycled Particulate Neoprene, Nitrile, and Epdm in Rubber Compounding. Rubber Chem. Technol. 1983;56(2):486-487. 
17. A. A. Yehia, M. A. Mull, M. N. Ismail, Y. A. Hefny and Abdel-Bary, E M. Effect of chemically modified waste rubber powder as a filler in natural rubber vulcanizates. $\mathbf{J}$. Appl. Polym. Sci. 2004;93(1):30-36.

18. Zhang, K, Shen, H, Zhang, X, Lan, R and Chen, H. Preparation and Properties of a Waterborne Contact Adhesive Based on Polychloroprene Latex and Styrene-Acrylate Emulsion Blend J. Adhesion Sci. Technol. 2009;23(1):163-175.

19. Sang Wook, P, Byung Chul, K and Dai Gil, L. Tensile Strength of Joints Bonded With a Nano-particle-Reinforced Adhesive. J. Adhesion Sci. Technol. 2009;23(1):95113.

20. Buchman, A, Dodiuk-Kenig, H, Dotan, A, Tenne, R and Kenig, S. Toughening of Epoxy Adhesives by Nanoparticles J. Adhesion Sci. Technol. 2009;23(5):753-768.

21. Likozar, B and Krajnc, M. A study of heat transfer during molding of elastomers. Chem. Eng. Sci. 2008;63(12):3181-3192.

22. Yan, L, Kou, K, Ji, T, Liang, G and Ha, E. Application of a new modified epoxy adhesive for bonding fluorine rubber to metal. J. Adhes. Sci. Technol. 2007;21(14831496.

23. Smitthipong, W, Nardin, M, Schultz, J and Suchiva, K. Adhesion and self-adhesion of rubbers, crosslinked by electron beam irradiation. Int. J. Adhes. Adhes. 2007;27(5):352-357.

24. Colom, X, Carrillo, F and Cañavate, J. Composites reinforced with reused tyres: Surface oxidant treatment to improve the interfacial compatibility. Compos. Pt. A-Appl. Sci. Manuf. 2007;38(1):44-50.

25. Van Duin, M, Liu, L, Luo, Y, Jia, D, Fu, W and Guo, B. Structure and Properties of Natural Rubber-Organoclay Nanocomposites Prepared by Grafting and Intercalating Method in Latex. J. Elastomer. Plast. 2006;38(2):147-161.

26. Leahy, W, Young, T, Buggy, M and Barron, V. A Study of Environmentally Friendly Titanium Pretreatments for Adhesive Bonding to a Thermoplastic Composite. Mat.-wiss. u. Werkstofftech. 2003;34(4):415-420.

27. Budrugeac, P. Thermal degradation of glass reinforced epoxy resin and polychloroprene rubber: the correlation of kinetic parameters of isothermal accelerated aging with those obtained from non-isothermal data. Polym. Degrad. Stabil. 2001;74(1):125-132. 
28. Arayasantiparb, D, McKnight, S and Libera, M. Compositional variation within the epoxy/adherend interphase. J. Adhesion Sci. Technol. 2001;15(12):1463-1484.

29. J. I. Kim, S. H. Ryu and Chang, Y W. Mechanical and dynamic mechanical properties of waste rubber powder/HDPE composite. J. Appl. Polym. Sci. 2000;77(12):2595-2602.

30. Cepeda-Jimenez, C M, Pastor-Blas, M M, Ferrandiz-Gomez, T P and MartinMartinez, J M. Surface Characterization of Vulcanized Rubber Treated with Sulfuric Acid and its Adhesion to Polyurethane Adhesive. J. Adhesion. 2000;73(2):135 - 160.

31. Jalilvand, A R, Ghasemi, I, Karrabi, M and Azizi, H. A study of EPDM devulcanization in a co-rotating twin-screw extruder. Iran. Polym. J. 2007;16(5):327335 .

32. Sutanto, P, Picchioni, F, Janssen, L, Dijkhuis, K A J, Dierkes, W K and Noordermeer, J W M. EPDM rubber reclaim from devulcanized EPDM. J. Appl. Polym. Sci. 2006;102(6):5948-5957.

33. Yun, J, Yashin, V V and Isayev, A I. Ultrasonic devulcanization of carbon blackfilled ethylene propylene diene monomer rubber. J. Appl. Polym. Sci. 2004;91(3):16461656.

34. Yun, J, and A. I. Isayev. Recycling of roofing membrane rubber by ultrasonic devulcanization. Polym. Eng. Sci. 2003;43(4):809-821.

35. An Duin, M, Noordermeer, J W, Verbruggen, M A L and Van der Does, L, Method for Devulcanizing Rubber with an mine. US Patent No 2003013776 (The Netherlands, 2003).

36. Pandey, K N, Setua, D K and Mathur, G N. Material behaviour: Fracture topography of rubber surfaces: an SEM study. Polym. Test. 2003;22(3):353-359.

37. Setua, D K. Scanning electron microscopy studies on thermo-oxidative ageing of polychloroprene rubber. Polym. Degrad. Stabil. 1985;12(2):169-180.

38. Ashalatha, P V, George, K E and Francis, D J. Scanning Electron Microscopic Studies of PP/EPDM/NR Ternary Blends. J. Elastomer. Plast. 1997;29(1):92-101.

39. Agarwal, K, Setua, D K and Sekhar, K. Scanning electron microscopy study on the influence of temperature on tear strength and failure mechanism of natural rubber vulcanizates. Polym. Test. 2005;24(6):781-789. 
40. Gisbert, A N. Investigación del reciclado de neumáticos a requisitos elastoméricos por técnicas de termocompresión. Valencia, 2003.

41. A. Nadal, C. Ferrer, M. Monzo and Lopez, J. Etude des mécanismes de recyclage des caoutchoucs provenant des déchets de pneus. Ann. Chim. Sci. Mat. 2008;33(3):179188.

42. Tripathy, A R, Morin, J E, Williams, D E, Eyles, S J and Farris, R J. A novel approach to improving the mechanical properties in recycled vulcanized natural rubber and its mechanism. Macromolecules. 2002;35(12):4616-4627.

43. Griffith, A A. The Phenomena of Rupture and Flow in Solids. 1921. 